Article

\title{
The Experimental Study of the Utilization of Recycling Aggregate from the Demolition of Elements of a Reinforced Concrete Hall
}

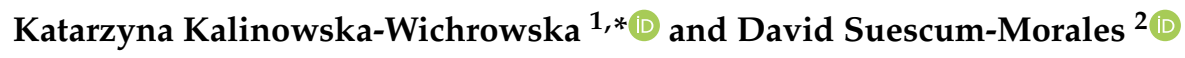 \\ 1 Faculty of Civil and Environmental Engineering, Bialystok University of Technology, 15351 Bialysto, Poland \\ 2 Construction Engineering Area, School of Engineering Sciences of Belmez, Universidad de Córdoba, \\ 14071 Córdoba, Spain; p02sumod@uco.es \\ * Correspondence: k.kalinowska@pb.edu.pl
}

Received: 3 June 2020; Accepted: 23 June 2020; Published: 25 June 2020

\begin{abstract}
The article shows a case study as to whether the thermal and mechanical recycling of concrete is suitable for concrete debris from the demolition of structural elements of a 30-year-old industrial hall. The experiment included 10 series of new composites made from heated recycled concrete aggregate (HRCA) subjected to different variants of heat treatment and one additional control series with only natural aggregate (NA). The compressive strength of the new concretes has been determined. The microscopic observations of HRCA have also been made. The test results revealed that proper heat treatment of concrete rubble makes it possible to obtain a high-quality recycled coarse aggregate, which can be used as a 100\% replacement for natural coarse aggregates in new concretes.
\end{abstract}

Keywords: industry concrete rubble; heated recycled concrete aggregate; reinforced construction waste

\section{Introduction}

The need to protect the earth's natural resources, mainly aggregates, and high energy consumption in the cement production process induces the reuse of concrete components and recycling. It is estimated that the concrete industry absorbs about 11 billion tons of natural aggregate per year [1] and the cement industry is responsible for about $8 \%$ of $\mathrm{CO}_{2}$ emissions into the atmosphere [2].

Construction and demolition waste $(\mathrm{CDW})$ is generated in the process of construction and demolition of buildings and other structures. Nowadays the growth of urbanization, construction of buildings, repairs and maintenance result in increased CDW [3]. According to the Waste Framework Directive (2008/98/EC) of the European Union and the EU Parliament, by 2020 a minimum of $70 \%$ of CDW should be recovered [4]. There are several countries that did not meet that objective in 2019 [5].

It is the reason that the use of an effective method of processing concrete debris in terms of the quality of recycled products obtained is the goal of the research of many scientists. One example is the C2CA method [6] which isdvanced technologies for the production of cement and clean aggregates from construction and demolition waste. The process consists of separating crushed coarse material from fine material based on the kinetic energy produced by the autogenic abrasion of those particles. Fine recycling fractions are obtained during the further cutting process to fractions 1-4 mm (Advanced Dry Recovery). The method allowed high-quality aggregates to be obtained from old mortar, but this did not result in the expected improvement in strength as a result of concretes made from that aggregate. Pepe et al. [7] analyzed the effectiveness of the autogenic cleaning process in a rotating drum by examining how the key physical properties of aggregates had been actually modified after applying different cleaning periods (in a range of 2 to $15 \mathrm{~min}$ ). The results showed a gradual decrease in water absorption by the aggregate, with an increase in treatment time from 2 to $15 \mathrm{~min}$. Based on 
preliminary findings, the processing times of 10 and $15 \mathrm{~min}$ have proved to be the most advantageous. The experimental results showed the effect of the proposed debris processing procedure in relation to the reduced water absorption of aggregates and the reduced content of adhering mortar, as well as improved compressive strength of concretes in relation to mechanical methods consisting only of multistage crushing in crushers. Another method of obtaining recycling aggregates is the Heating Rubble Method [8]. This method uses a thermal container and two tube mills. In the thermal container the concrete debris is heated to a temperature of about $300^{\circ} \mathrm{C}$. As a result of the partial dehydration of the cement, the local loss of adhesion between the cement mortar and the aggregate occurred, which at a later stage of abrasion in mills caused the separation of the aggregate from the mortar. The result was about $35 \%$ coarse aggregate, $21 \%$ fine aggregate, and as much as $44 \%$ dust. Due to only partial dehydration of the cement at $300{ }^{\circ} \mathrm{C}$ it was necessary to use two tube mills to separate the mortar from the aggregate more effectively. Due to the formation of a significant amount of dust, the use of bag filters was indispensable [8]. Tsujino et al., and Choi et al. [9,10] showed that microwave heating was an effective method of recovering high-quality recycled aggregate and did not affect its structure. The microwave energy was used to weaken binders containing a dielectric in the form of $\mathrm{Fe}_{2} \mathrm{O}_{3}$. During microwave heating in concrete the microcracks appeared due to the hydrate dehydration reaction. This, in turn, led to the decomposition of $\mathrm{Ca}(\mathrm{OH})_{2}$ and $\mathrm{CaCO}_{3}$, causing both the weakening of the cement matrix strength and the rupture of the aggregate-cement matrix joints. The chemical reactions that occurred during heating are summarized in Equations (1) and (2) [11,12]. The method is relatively new and no larger scale research has been carried out. Linsz and Múller [13] proposed using sound pulses generated underwater through electric discharges. The induced water ripple, at the interface of elements of different density, caused cyclical compressive and tensile forces, which broke the bond between the aggregate and the cement mortar.

$$
\begin{aligned}
\mathrm{Ca}(\mathrm{OH})_{2} & \rightarrow \mathrm{CaO}+\mathrm{H}_{2} \mathrm{O} . \\
\mathrm{CaCO}_{3} & \rightarrow \mathrm{CO}_{2}+\mathrm{CaO} .
\end{aligned}
$$

Robayo-Salazar et al. [14] indicated the use of a $\mathrm{NaOH}$ solution as a way to improve the quality of secondary aggregates (both fine and coarse). Wang et al. [15] proved that soaking recycled aggregates in acetic acid was more effective than the environmentally friendly method described above. Compared with existing chemical processing methods using strong acids the new method does not introduce any harmful chemicals into the secondary aggregate. The analysis revealed that soaking in an acetic acid solution effectively removed old cement mortar from the surface of recycled aggregate and the absorption of water by the aggregate dropped by $9-19 \%$. It was found that $24 \mathrm{~h}$ soaking in 3\% acetic solution was sufficient and the strength results of concrete made with recycled aggregate cleaned by this method were improved.

The methods described above do not resolve the development of concrete debris in a comprehensive manner, i.e., they do not provide a solution for the treatment of the obtained dust fraction $<4 \mathrm{~mm}$, and the quality of recycled coarse aggregates does not allow them to be used as a $100 \%$ substitute for natural aggregates.

Kalinowska-Wichrowska et al. [16] proposed a new thermal-mechanical method allowing for the overall processing of concrete debris, which resulted in a high-quality recycling aggregate and recycling mortar. The coarse aggregate obtained according to that method improved the concrete strength parameters. Tests were carried out on concrete debris made in laboratory conditions (from cutting concrete samples of a known composition and age). This article presents verification of that method in relation to concrete debris obtained from the demolition of structural elements of a 30-year-old industry hall. The possibility of obtaining high-quality recycled aggregates from the processing of old construction elements and buildings is also a very important matter for entrepreneurs who can effectively convert debris into a high-quality recycled aggregate on the construction site and use it for new concrete, giving an added value to such waste. This saves natural resources, promotes the circular 
economy of aggregates, is an example of concrete waste management and facilitates the disposal of waste concrete.

\section{Materials and Methods}

\subsection{The Elements of the Reinforced Hall Used for the Recycling Process}

Reinforced concrete columns were obtained during the demolition of a 30-year-old industry hall. The concrete of those elements was classified as C30/37 strength class according to Eurocode 2 (EN 1992-1-1:2004) [17]. In the next step the columns $(40 \times 40 \times 360 \mathrm{~cm})$ were crushed in a mobile crushing plant into smaller parts and the steel was separated. The concrete debris (Recycling Concrete Aggregate) was then transported to the laboratory. The size of the RCA was $<4 \mathrm{~cm}$ according to PAT.229887 [18]. The origin of the natural aggregate used in the concrete was gravel.

\subsection{The Recycling Process of the RCA (Thermo-Mechanical Treatment According to PAT.229887)}

In the next step, the RCA was calcinated in the laboratory furnaces. Calcination of the recycled aggregate was necessary in order to dehydrate the cement paste and to reduce the adhesion of the hardened mortar from the aggregate grains, and it is a main assumption of the method described in PAT.229887 [18]. After calcination and cooling the recycled material was mechanically processed in a Los Angeles machine. The calcinating time was 30-70 $\mathrm{min}$ and the temperature was $400-800{ }^{\circ} \mathrm{C}$ according to the experiment plan. In such a temperature range the chemical reactions shown in Equations (1) and (2) may occur. After the full recycling process, the HRCA (heated recycled concrete aggregate $\mathrm{d} \geq 4 \mathrm{~mm}$ ) was separated from fine fractions (FA), $\mathrm{d}<4 \mathrm{~mm}$, and used for furthers tests.

\subsection{Materials}

The Portland cement CEM I 32.5R following the requirements of the EN 197-1:2011 standard [19] was used for the manufacturing of the concrete composites. The natural aggregate (NA), sand $0-2 \mathrm{~mm}$ and gravel 2-4 mm, 4-8 and 8-16 $\mathrm{mm}$ was used. The heated recycled concrete aggregate fraction of 4-16 mm was used; the process of obtaining the HRCA is described in Section 2.1. The HRCA was used for new concrete mixtures as a $100 \%$ replacement of NA with a fraction of $4-16 \mathrm{~mm}$.

\subsection{Concrete Mixtures}

The new concrete mixtures with the HRCA used as a 100\% replacement of NA (fraction 4-16 mm) and control mixtures (only with NA) were prepared. In the main concrete mixture (for $1 \mathrm{~m} 3$ ) $320 \mathrm{~kg}$ of cement, $698 \mathrm{~kg}$ of sand (0-2 mm), $199 \mathrm{~kg}$ of gravel (2-4 mm), $499 \mathrm{~kg}$ of gravel (4-8mm) and $599 \mathrm{~kg}$ of gravel $(8-16 \mathrm{~mm})$ were used, and $\mathrm{w} / \mathrm{c}$ ratio was 0.45 . In other mixtures the amount of the HRCA was modified according to its density. In the series $1-10,100 \%$ of the amount of coarse NA was replaced by the HRCA after thermal and mechanical treatment (calcination temperature and time of treatment were based on the assumptions of the experimental plan, which is described in detail in Section 3). Series 11 was prepared with $100 \%$ of NA $(0-16 \mathrm{~mm})$ and did not contain any HRCA.

\subsection{Methods}

\subsubsection{Test Methods for Physical and Mechanical Properties}

The samples of composites $(10 \times 10 \times 10 \mathrm{~mm})$ were prepared in accordance with EN 12390-1 [20]. After 28 days of curing the compressive strength tests were carried out in accordance with EN 12390-3 [21].

\subsubsection{Microstructural Research}

The microstructural analysis of the surface of the RHCA was carried out using a scanning electron microscope (SEM) and Energy Dispersive X-ray spectroscopy (EDS). The microstructure measurements 
were performed on Tescan's high resolution SEM Mira III with X-ray Microanalysis (based on EDS-X-ray Spectrometry) Aztek Automated production of Oxford instruments.

\section{Experimental Plan}

For the factors determining the characteristics of the HRCA as a substitute for NA the experiment was performed based on two variables: $X_{1}$-the temperature of concrete rubble calcination and $X_{2}$-the time of calcination treatment. The range of variation and the levels of analyzed factors are shown in detail in Table 1.

Table 1. The rotatable central composite design of experiment.

\begin{tabular}{ccccc}
\hline \multirow{2}{*}{ Series } & \multicolumn{2}{c}{ Real Values } & \multicolumn{2}{c}{ Normalized Values } \\
\cline { 2 - 5 } & $\boldsymbol{X}_{\mathbf{1}},{ }^{\circ} \mathbf{C}$ & $\boldsymbol{X}_{\mathbf{2}}, \mathbf{m i n}$ & $\boldsymbol{x}_{\mathbf{1}}$ & $\boldsymbol{x}_{\mathbf{2}}$ \\
\hline 1 & 459 & 36 & -1 & -1 \\
2 & 459 & 64 & -1 & 1 \\
3 & 741 & 36 & 1 & -1 \\
4 & 741 & 64 & 1 & 1 \\
5 & 400 & 50 & -1414 & 0 \\
6 & 800 & 50 & 1414 & 0 \\
7 & 600 & 30 & 0 & -1414 \\
8 & 600 & 70 & 0 & 1414 \\
9 & 600 & 50 & 0 & 0 \\
10 & 600 & 50 & 0 & 0 \\
\hline
\end{tabular}

The calcination temperatures were selected according to the effects of phase changes. In temperatures up to $350-400{ }^{\circ} \mathrm{C}$ dehydration of CSH silicates, hydrated aluminates and aluminum calcium sulphates should occur along with gypsum decomposition. However, in temperatures up to $400-550{ }^{\circ} \mathrm{C}$ the portlandite should break down into $\mathrm{CaO}$ and $\mathrm{H}_{2} \mathrm{O}$, according to Equation (1) [11,12,22-24]. In the range of 550-800 ${ }^{\circ} \mathrm{C}$ the decomposition of calcium carbonate should occur according to Equation (2) and $\mathrm{CaO}$ should appear [11,23-25]. The temperature of $600^{\circ} \mathrm{C}$ is the center of the plan, and other extremes such as $400^{\circ} \mathrm{C}$ and $800^{\circ} \mathrm{C}$ are the star points and result from the design of the adopted rotational plan.

The statistical analysis was carried out in accordance with the rotatable central composite design with a double repetition of the experiment at a central point. The design of the experiment (DoE) allowed the checking of the repeatability of the results to find which input factors and their interactions could significantly influence the output properties, to calculate the regression equation and to check its adequacy with the test results. The compressive strength of composites with the HRCA and NA was selected for analysis.

On the basis of the above-mentioned variables the experimental plan including 10 test series and 1 additional control series was established. Table 1 shows the detailed experimental plan with the actual and normalized values of the variables.

Apart from the series described in Table 1, the additional control series (11) without HRCARCARHr was prepared.

Combinations of the actual values of the examined factors $X_{1}$ and $X_{2}$ were established on the basis of the assumptions of the design of experiment [17]. The dimensionless normalized values- $x_{1}$ and $x_{2}$-related to them were used to develop the functions describing the influence of the analyzed factors on the resulting quantities.

The test results were statistically analyzed in order to determine the approximating function describing the influence of the tested variables on the selected properties of the composites with RCA. The analyses included analysis of variance, calculation of regression coefficients and assessment of the significance of 
regression coefficients. The function describing the changes of the physical and mechanical properties of the cement composites took the form of a second-degree polynomial (Equation (3)):

$$
y=b_{0}+b_{1} x_{1}+b_{2} x_{2}+b_{3} x_{1} x_{2}+b_{4} x_{1}^{2}+b_{5} x_{2}^{2}
$$

where: $y$ is the dependent variable, explained; $x_{1}, x_{2}$ are the independent variables; $b_{i}$ are the coefficients and $b_{0}$ is the free term in expression.

Calculations were performed according to [26] using Statistica Version 13 software.

\section{Results and Discussion}

\subsection{The Properties of NA and HRCA}

Table 2 shows the main properties of aggregates used in the cement composites mixtures.

Table 2. The properties of NA and HRCA used in tests.

\begin{tabular}{ccccc}
\hline \multirow{2}{*}{ Properties } & \multicolumn{2}{c}{ NA } & \multicolumn{2}{c}{ HRCA } \\
\cline { 2 - 5 } & $\mathbf{4 - 8} \mathbf{~ m m}$ & $\mathbf{8 - 1 6} \mathbf{~ m m}$ & $\mathbf{4 - 8} \mathbf{~ m m}$ & $\mathbf{8 - 1 6} \mathbf{~ m m}$ \\
\hline Water absorption $(\mathrm{WA}), \%$ & 1.3 & 1.0 & 2.5 & 1.8 \\
Specific gravity $(\rho), \mathrm{g} / \mathrm{cm}^{3}$ & 2.67 & 2.67 & 2.69 & 2.68 \\
Volume density $\left(\rho_{r d}\right), \mathrm{g} / \mathrm{cm}^{3}$ & 2.64 & 2.64 & 2.53 & 2.59 \\
\hline
\end{tabular}

The specific gravity and volume density of the HRCA were comparable to the natural aggregates; the highest difference was the water absorption, which was around two times higher than for NA. This conforms with findings of other authors $[25,27]$.

\section{SEM Images of Analyzed HRCA}

In order to analyze the structure of recycled aggregates after mechanical or thermal-mechanical treatment, observations were made using a scanning microscope. Figures 1-3 show scanning images of the HRCA with measuring areas marked. Figure 1 shows the heated recycled concrete aggregate with research zones (HRCA). On one hand, at low magnification it may appear that the interface transition zone is dense and that no cracks appear.

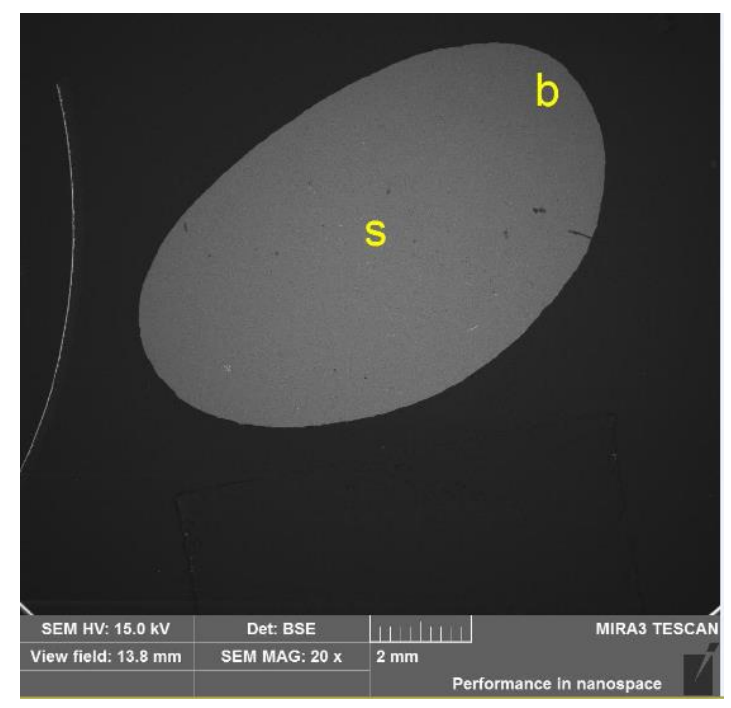

Figure 1. Heated recycled concrete aggregate (HRCA) with research zones, $\mathrm{s}$ is the center; $\mathrm{b}$ is the corner. 


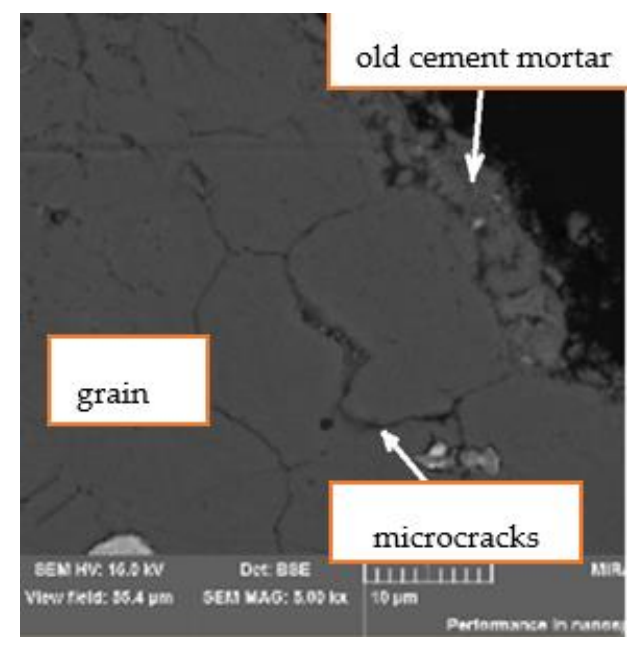

Figure 2. The corner part of HRCA.

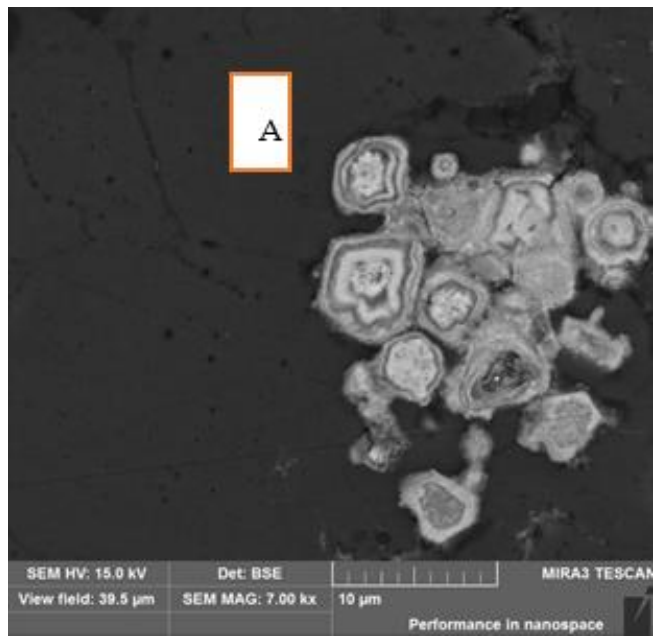

Figure 3. The corner part of HRCA; A-is alite, belite and calcium silicate hydrates (CSH) from old cement paste.

On the other hand, the microstructure of the sample of the recycled aggregate after thermal-mechanical treatment at a high magnification was not complete and had visible microcracks (Figures 2 and 3), which were concentrated mainly in the outer part of the preparation (effect of thermal-mechanical treatment). That crack was observed by Yekai Yang et al. [28] when they heated a high strength concrete at $600{ }^{\circ} \mathrm{C}$. The main components of the sample include $\mathrm{Ca}$ and $\mathrm{O}$. This is in accordance with Equations (1) and (2). Such composition indicates that there were no unhydrated particles (Figure 3). In the central region the secondary element was $\mathrm{Si}$, and the trace ones were primarily $\mathrm{Al}, \mathrm{Mg}, \mathrm{Fe}$ and $\mathrm{K}$. It was similar in the marginal area, where $\mathrm{Al}$ was a secondary element. The spot analysis revealed that the matrix of the preparation was calcium carbonate. Inclusions of iron oxide and silica were also dispersed in the material.

Figure 3 shows the corner part of the HRCA. It was observed that unhydrated particles (alite and belite) existed, which may have been caused by the heat treatment and calcium silicate hydrates (CSH). The appearance of those chemical phases could lead to an improvement in mechanical properties when that residue is used as a substitute for natural sand [29]. Table 3 shows the elemental composition of individual aggregate areas, which helped to identify the phases, mainly those on the surface in the adjacent mortar layer. 
Table 3. Elemental composition of the analyzed samples of the HRCA (\% by mass) depending on the tested area.

\begin{tabular}{ccc}
\hline Spectrum Label & HRCA (s)-Middle & HRCA (b)-Corner \\
\hline $\mathrm{O}$ & 53.03 & 50.00 \\
$\mathrm{Mg}$ & 0.33 & 0.38 \\
$\mathrm{Al}$ & 0.36 & 1.01 \\
$\mathrm{Si}$ & 1.29 & 3.95 \\
$\mathrm{~K}$ & 0.28 & 0.84 \\
$\mathrm{Ca}$ & 44.44 & 43.41 \\
$\mathrm{Fe}$ & 0.28 & 0.41 \\
\hline
\end{tabular}

An area of high potassium and phosphorus content was also identified. At the edge of the sample the layers of a different morphology than the rest of the sample came from the components of the old cement paste (Figure 3). Due to the elements identified there ( $\mathrm{Ca}, \mathrm{Al}, \mathrm{Si}$ ) it may be concluded that they are calcium aluminosilicates, among other things.

\subsection{The Properties of Hardened Concrete with HRCA}

\section{Compressive Strength}

The average compressive strength results obtained for the test series in comparison to the control samples (series 11) are shown in Figure 4.

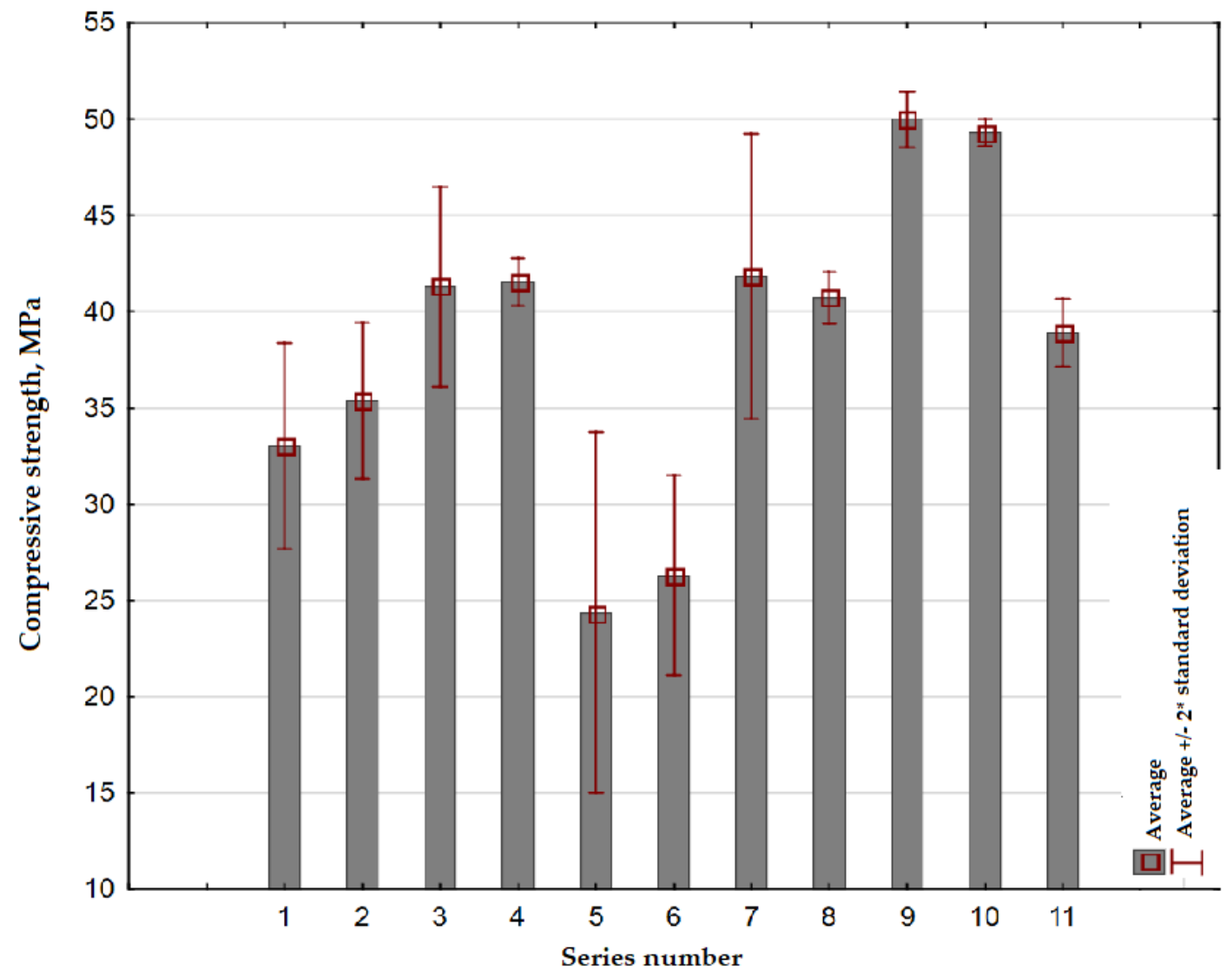

Figure 4. The compressive strength of composites after 28 days.

It was observed that the most favorable values of compressive strength were obtained for the aggregates roasted at $600{ }^{\circ} \mathrm{C}$ (series 9,10 ). This may result from the amount of $\mathrm{CaO}$ generated at such temperature (Equations (1) and (2) together with a not too high formation of microcracks in the HRCA). 
The compressive strength of those samples was more than $20 \%$ higher than in the results obtained in the case of the control samples (from natural aggregate, series 11). The lowest concrete strength results were in turn obtained for processing debris at $400{ }^{\circ} \mathrm{C}$ and $800{ }^{\circ} \mathrm{C}$ and they were lower by about $30 \%$ compared with the control series.

It can also be seen that despite extending the roasting time of debris up to $70 \mathrm{~min}$ (series 7) or shortening it to $30 \mathrm{~min}$ (series 8) while maintaining a temperature of $600{ }^{\circ} \mathrm{C}$ there was no improvement of strength parameters, but of their decrease. This, in addition to the properly selected roasting temperature, proved that the calcination time also plays an important role. A very short calcination time may result in not reaching the indicated temperature evenly throughout the aggregate and the appearance of non-binding materials (for example $\mathrm{CaO}$, i.e., free lime).

The changes in the cement composite compressive strength depending on the calcination temperature of rubble $\left(x_{1}\right)$ and the treatment time $\left(x_{2}\right)$ are presented in Figure 5. The function describing the dependence of the compressive strength on the tested variables for composites with HRCA is expressed in the following equation:

$$
Y=49.65+3.90 x_{1}-9.15 x_{1}^{2}-3.68 x_{2}^{2} \quad R^{2}=0.90 .
$$

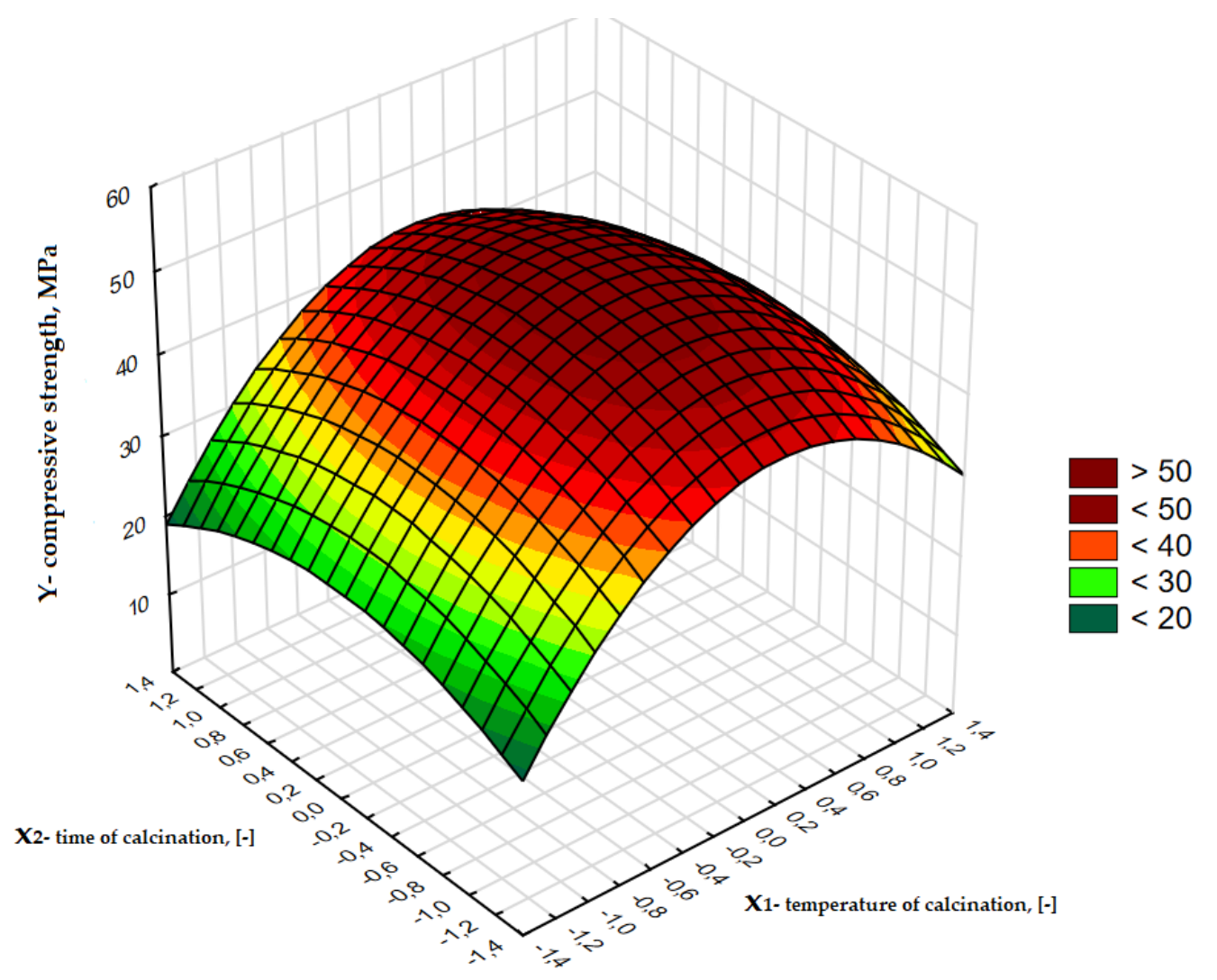

Figure 5. The changes in compressive strength of concrete composites (MPa), depending on $\mathrm{x}_{\mathbf{1}}$ and $\mathrm{x}_{\mathbf{2}}$.

As a result of the statistical analysis of the test results it was observed that the highest compressive strength parameters after 28 days of curing $(Y)$ had been obtained for a simultaneous increase of temperature $\left(X_{1}\right)$ up to $600{ }^{\circ} \mathrm{C}$ and a roasting time $\left(X_{2}\right)$ of $50 \mathrm{~min}$. When using a roasting temperature of about $600{ }^{\circ} \mathrm{C}$ an improvement in the compressive strength was observed compared with debris roasted at lower temperatures. An increase in the roasting temperature to $800{ }^{\circ} \mathrm{C}$ resulted in a decrease of the compressive strength of the concrete obtained, probably due to the breakdown of calcite present in the old cement mortar on the surface of the aggregate from recycling and the release of $\mathrm{CO}_{2}$. Another cause could be the appearance of very wide microcracks. In addition, often such a high roasting 
temperature can damage the aggregate grain itself (leading to its swelling), more often when it is a carbonate aggregate as used here.

The recycled aggregate after the thermal-mechanical treatment was characterized by an uneven, rough surface and adhering remains of porous mortar. The diffractometric examination of the old mortar revealed the presence of calcite, free lime and CSH phases [30]. After adding the recycling aggregate to the concrete mix the new grout penetrated into micro-cavities formed on the surface of the aggregate grain after the thermal-mechanical treatment. In addition, there was a process of rehydration of the free lime as a product of the breakdown of portlandite during processing at temperatures higher than $500{ }^{\circ} \mathrm{C}$. In addition to the phenomena described above, there was also a classic process of hydration of the cement introduced as a binder into the concrete mix in order to produce the typical phases (alite, belite, ettryngite, calcite, portlandite and CSH). The new cement paste diffused towards the porous structure of the old grout, thus sealing the contact zone between the recycled aggregate and new cement paste. Due to the compact structure of the contact zone of the gravel recycling aggregate after thermal and mechanical treatment, the, results of compressive strength of new concrete with HRCA were by over $20 \%$ higher than in case of concrete with NA. The described relationships were also obtained as a result of tests of recycling aggregate from debris obtained by crushing the concrete samples made in the laboratory, whose age usually did not exceed several years [30]. Therefore, it was very important to check the assumed thermal-mechanical treatment in case of debris from the structural elements (columns) of the old hall and the quality of the recycling aggregate exposed for many years to the environment.

\section{Conclusions}

The tests revealed that the proposed method of thermal-mechanical treatment of concrete debris from the demolition of structural elements of a 30-year-old industrial hall allows to obtain high-quality, thick recycling aggregate, which can be successfully used as a complete replacement for the required natural coarse aggregate in a new concrete. Considering the earlier tests carried out mainly on uncontaminated debris produced in the laboratory, of a known composition and a fairly short age (several years), it should be considered that the method is also useful for the recycling of old concrete components.

The strength tests of new concretes using the recycled concrete rubble calcinated at $600{ }^{\circ} \mathrm{C}$ proved that the assumed treatment temperature is the most favorable in terms of obtained results. An important role is also played by the time of thermal treatment, which should oscillate around $50 \mathrm{~min}$.

Considering the results and a fairly simple recycling process with the vision of the overall use of waste material, it is possible to introduce the method on an industrial scale or to apply it in prefabrication plants.

Author Contributions: writing-original draft preparation, K.K.-W.; writing-review and editing, D.S.-M. All authors have read and agreed to the published version of the manuscript.

Funding: This research received no external funding.

Acknowledgments: This research were performed during Katarzyna Kalinowska-Wichrowska's STSM COST RESTORE GRANT ECOST-STSM-CA16114-030120-115108 and the Bialystok University of Technology project no WZ/WB-IIL/3/2020 funded by the Polish Ministry of Science and Higher Education D. Suescum-Morales would like to acknowledge at MECD-Spain (http://www.mecd.gob.es/educacion-mecd/) (FPU 17/04329)

Conflicts of Interest: The authors declare no conflict of interest.

\section{References}

1. Jin, R.; Chen, Q. Investigation of concrete recycling in the U.S. construction industry. Procedia Eng. 2015, 118, 894-901. [CrossRef]

2. Chen, C.; Habert, G.; Bouzidi, Y.; Jullien, A. Environmental impact of cement production: Detail of the different processes and cement plant variability evaluation. J. Clean. Prod. 2010, 18, 478-485. [CrossRef] 
3. Rodríguez, G.; Sáez del Bosque, I.F.; Asensio, E.; Sánchez de Rojas, M.I.; Medina, C. Construction and demolition waste applications and maximum daily output in Spanish recycling plants. Waste Manag. Res. 2020, 38, 423-432. [CrossRef] [PubMed]

4. Directive, S.F. Directive 2008/56/EC of the European Parliament and of the Council; Official Journal of the European Union: Luxembourg, 2008; pp. 19-40.

5. Eurostat, Recovery Rate of Construction and Demolition Waste. 2019. Available online: https://ec.europa.eu/ eurostat/databrowser/view/cei_wm040/default/table?lang=en (accessed on 3 May 2020).

6. Lotfi, S.; Eggimann, M.; Wagner, E.; Mróz, R.; Deja, J. Performance of recycled aggregate concrete based on a new concrete recycling technology. Constr. Build. Mater. 2015, 95, 243-256. [CrossRef]

7. Pepe, M.; Filho, R.T.; Koenders, E.A.B.; Martinelli, E. Alternative processing procedures for recycled aggregates in structural concrete. Constr. Build. Mater. 2014, 69, 124-132. [CrossRef]

8. Shima, H.; Tateyashiki, H.; Matsuhashi, R.; Yoshida, Y. An advanced concreto recycling technology and its applicability assessment through input-output analysis. J. Adv. Concr. Technol. 2005, 3, 53-67. [CrossRef]

9. Choi, H.; Kitagaki, R.; Noguchi, T. Effective recycling of surface modificationaggregate using microwave heating. J. Adv. Concr. Technol. 2014, 12, 34-45. [CrossRef]

10. Tsujino, M.; Noguchi, T.; Tamura, M.; Kanematsu, M.; Marujama, I. Application of conventionally recycled coarse aggregate to concrete structure by Surface modification treatment. J. Adv. Concr. Technol. 2007, 5, 13-25. [CrossRef]

11. Esquinas, A.R.; Ledesma, E.F.; Otero, R.; Jiménez, J.R.; Fernández, J.M. Mechanical behaviour of self-compacting concrete made with non-conforming fly ash from coal-fired power plants. Constr. Build. Mater. 2018, 182, 385-398. [CrossRef]

12. Kaliyavaradhan, S.K.; Ling, T.C. Potential of $\mathrm{CO}_{2}$ sequestration through construction and demolition (C\&D) waste-An overview. J. CO2 Util. 2017, 20, 234-242. [CrossRef]

13. Linsz, E.; Múller, A. High-performance sonic impulses-an alternative method for processing of concrete. Int. J. Miner. Process. 2004, 74, 199-208. [CrossRef]

14. Robayo-Salazar, R.A.; Rivera, J.F.; de Gutiérrez, R.M. Alkali-activated building materials made with recycled construction and demolition wastes. Constr. Build. Mater. 2017, 149, 130-138. [CrossRef]

15. Wang, L.; Wang, J.; Qian, X.; Guo, J. An environmentally friendly method to improve the quality of recycled concrete aggregates. Constr. Build. Mater. 2017, 144, 432-441. [CrossRef]

16. Kalinowska-Wichrowska, K.; Pawluczuk, E.; Bołtryk, M. Waste -free technology for recycling concrete rubble. Constr. Build. Mater. 2020, 234, 117407. [CrossRef]

17. PN-EN 1992-1-1: 2004/AC (2010) Eurocode2, Design of Concrete Structures-Part 1-1: General Rules and Rules for Buildings; European Standard; CEN: Brussels, Belgium, 2010.

18. Bołtryk, M.; Kalinowska-Wichrowska, K.; Pawluczuk, E. Method for Separation of Set Cement Mortar from Coarse Aggregate and for Crushing that Mortar, and the Device for the Application of this Method. Patent 229887, 2018.

19. EN 197-1:2011 Cement. Composition, Specifications and Conformity Criteria for Common Cements; European Committee for Standardization: Brussels, Belgium, 2011.

20. EN 12390-1: 2012 Testing Hardened Concrete-Part 1: Shape, Dimensions and Other Requirements for Speciments and Moulds; British Standard Instituition: London, UK, 2012.

21. EN 12390-3:2019 Testing Hardened Concrete_Part 3: Compressive Strength of Test Specimens; British Standards Institution: London, UK, 2019.

22. Ramachandran, V.S.; Paroli, R.M.; Beaudoin, J.J.; Delgado, A.H. Handbook of Thermal Analysis of Construction Materials; Noyes Publications/William Andrew Publishing: New York, NY, USA, 2003.

23. Hernández-Olivares, F.; Mayor-Lobo, P. Experimental assessment of commercial one-coat renders for buildings faades. Constr. Build. Mater. 2011, 25, 156-162. [CrossRef]

24. Ledesma, E.F.; Jiménez, J.R.; Ayuso, J.; Fernández, J.M.; De Brito, J. Maximum feasible use of recycled sand from construction and demolition waste for eco-mortar production-Part-I: Ceramic masonry waste. J. Clean. Prod. 2015, 87, 692-706. [CrossRef]

25. Gonzalez-Corominas, A.; Etxeberria, M. Properties of high performance concrete made with recycled fine ceramic and coarse mixed aggregates. Constr. Build. Mater. 2014, 68, 618-626. [CrossRef]

26. Montgomery, D.C. Design and Analysis of Experiments; Wiley\&Sons Inc.: Tempe, AZ, USA, 2017. 
27. Tam, V.W.Y.; Soomro, M.; Evangelista, A.C.J. A review of recycled aggregate in concrete applications (2000-2017). Constr. Build. Mater. 2018, 172, 272-292. [CrossRef]

28. Yang, Y.; Wu, C.; Liu, Z.; Liang, X.; Xu, S. Experimental investigation on the dynamic behaviors of UHPFRC after exposure to high temperature. Constr. Build. Mater. 2019, 227, 116679. [CrossRef]

29. Shui, Z.; Xuan, D.; Wan, H.; Cao, B. Rehydration reactivity of recycled mortar from concrete waste experienced to thermal treatment. Constr. Build. Mater. 2008, 22, 1723-1729. [CrossRef]

30. Kalinowska-Wichrowska, K.; Kosior-Kazberuk, M.; Pawluczuk, E. The Properties of Composites with Recycled Cement Mortar Used as a Supplementary Cementitious Material. Materials 2019, 13, 64. [CrossRef] [PubMed]

(C) 2020 by the authors. Licensee MDPI, Basel, Switzerland. This article is an open access article distributed under the terms and conditions of the Creative Commons Attribution (CC BY) license (http://creativecommons.org/licenses/by/4.0/). 